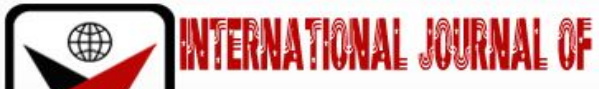

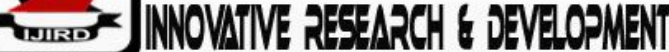

ISSN 2278 - 0211 (Online)

\section{Improving Youth and Adult Multillingual Basic Literacy Education in the North Central Geopolitical Zone of Nigeria}

\begin{tabular}{|c|}
\hline Rosemary O. Igbo \\
Professor, Department of Continuing Education and Community Development, \\
IBB University, Lapai, Nigeria \\
Muriana O. Ojuola \\
Professor, Department of Continuing Education and Community Development, \\
IBB University, Lapai Nigeria \\
Adeshina A. Olojede \\
Senior Lecturer, Department of Continuing Education and community Development, \\
IBB University, Lapai Nigeria \\
Adebiyi A. Adelakun \\
Senior Lecturer, Department of Continuing Education and Community Development, \\
IBB University, Lapai Nigeria
\end{tabular}

\begin{abstract}
:
This empirical study was carried out to determine skills achievement and existing gaps in the multilingual basic literacy education practice in Niger State, Nigeria. Participatory and collaborative research techniques were adopted through participatory rural appraisal (PRA) and focus group meetings (FGM). The FGMs were held in the three senatorial zones in Niger State by drawing 146 stakeholders as participants. The communities provided answers to the initial questions and explained the situation in the first stage of the research. The second stage assessed the context in terms of the identified learning expectations, language issues, contents, facilitators, facilitation and other cultural elements. The findings specified among other things that although learners exhibited varying levels literacy skills; the literacy education practice in the zones were devoid of adequate/ appropriate resources for effective facilitation of literacy learning programmes relative to current global standards. These include absence of information communication technology (ICT), e-learning, trained facilitators, and current primers. The recommendations emphasized participatory decision making among the stakeholders concerning programme timing, contents, language of instruction, participation, enrolments and mode of delivery in the face of globalization.
\end{abstract}

Keywords: Multilingual, literacy, skills, achievement, gaps

\section{Background of the Study}

Nigeria is committed to the actualization of Education for All (EFA) and Sustainable Development Goals intended to achieve 100\% enrollment and completion of basic education by all citizens within the soon coming years, no matter their life circumstances. This commitment has become more relevant with statistics showing that seventeen (17) out of thirty - seven (37) States in Nigeria could not achieve the Education for All goal 4 by 2015, because they had youth and adult literacy rates between 14.5 to $49.3 \%$. These included mainly the northern States which had considerably large population of pastoralists and rural learners. A two pronged approach to literacy was envisioned to accelerate the process through significant advocacy and investments that would ensure wider access and inclusion of out-of-school children, youths and adults in adequate basic education and effective learning opportunities, to develop literacy skills: First was the development of a policy guideline for adult and non - formal education to set up structures for promoting diverse learning through the guideline. This approach was actualized to include the multilingual dimension to literacy education that would validate the pivotal role of languages in achieving the skill expectations (NMEC, 2017). The second approach was to dispel the narrow-mindedness and uncertainty about local languages and eradicate the often hidden attempt to discredit them as being an obstacle to learning and acquisition of literacy skills (Qane and Glanz, 2010). 
Niger State in the North Central Zone of Nigeria was the focus of this action research. The decision to study Niger State was reached through a randomized process involving the six States in north-central Nigeria and the Federal Capital Territory. Niger State is The Power State of Nigeria. It is the largest state in Nigeria by land mass (76,363 Square kilometers). It was created out of north western Nigeria in 1976 and it is divided into 25 Local Government Areas. The State was named after the Niger River and it houses the two Nigerian major Hydro - electric power stations, the Kainji dam and Shiroro dams. Agriculture is the major occupation of the people. The Gwari, Koro, Kadara and Kambari are noted for yam and guinea corn production while the Nupes are the major producers of rice, beans and melons. The Hausa and Fulani are well known for animal husbandry. Niger State has abundant natural resources such as lime stone, glass sands, chalk, copper, while surveys carried out have shown deposit of gold and marble in parts of Minna. Niger State has an estimated population of about 3,950,249 by the 2006 census. The three principal ethnic groups of the State are Nupe, Hausa and Gwari other groups include Koro, Kagara, Kambari, Kammuku, Pangu, Bassa, Bauchi, Fulani, Dukuwa, Gabo, Godara, Ganagana, Mauchi, Ayadi, Ingwa, Dido, Kadade, AbiShiwa and the Shigini.

The following table represent spoken languages in various political zones of Niger State, with which the National Commission for Mass Literacy Adult and Non-formal Education (NMEC) developed some of the existing primers:

\begin{tabular}{|c|c|c|}
\hline Senatorial Zones & Local Government Areas (LGAS) & Language of Instruction \\
\hline A & Lapai & Nupe, Hausa, Yoruba, English \\
\hline B & Paikoro & Hausa, Nupe, , Gbagi; English \\
\hline C & Wushishi & Hausa, English \\
\hline
\end{tabular}

Table 1: Spoken Languages in the Three Senatorial Zones in Niger State

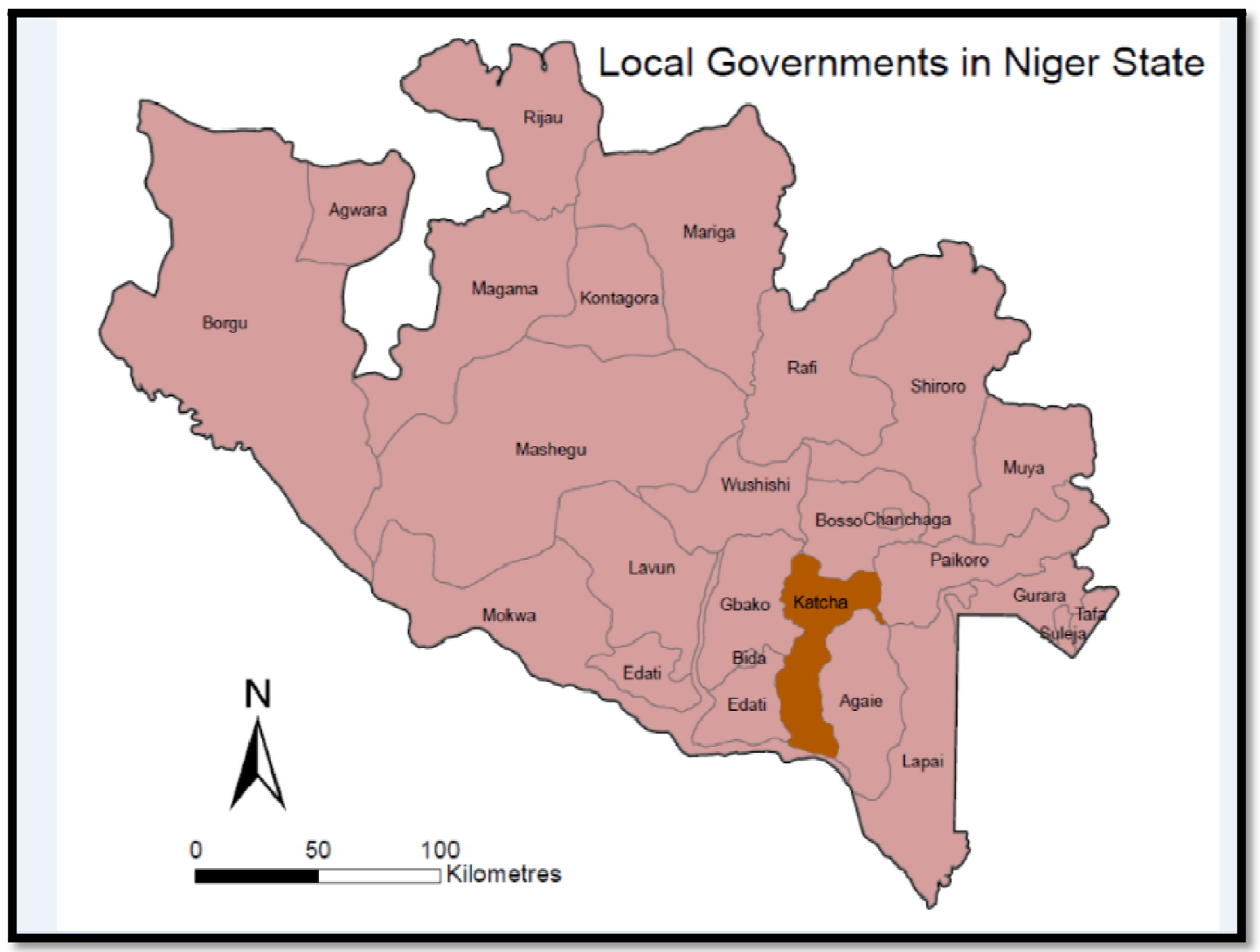

Figure 1: Niger Sate, Nigeria

\subsection{Justification and Purpose of the Research}

Niger State within the north central geopolitical zone is in need of accelerated basic literacy process; through investments in structures that would facilitate wider access because she has a mean literacy level estimated at 53\%, which is a borderline rating relative to other states in the geo - political zone. 


\begin{tabular}{|c|c|c|c|c|c|c|c|c|}
\hline Zone & Male & Female & Total & Literate & Literate & $\begin{array}{c}\text { \% } \\
\text { literate }\end{array}$ & $\begin{array}{c}\text { \% } \\
\text { Illiterate }\end{array}$ & Total \\
\hline Benue & $2,485,533$ & $2,445,602$ & $4,931,135$ & $2,416,256$ & $2,514,879$ & 49 & 51 & 100 \\
\hline Kogi & $1,939,353$ & $1,902,531$ & $3,841,884$ & $2,305,130$ & $1,536,754$ & 60 & 40 & 100 \\
\hline Kwara & $1,383,922$ & $1,358,171$ & $2,742,093$ & $1,398,467$ & $1,343,626$ & 51 & 49 & 100 \\
\hline Nassarawa & $1,094,124$ & $1,072,996$ & $2,167,120$ & 910,190 & $1,256,930$ & 42 & 58 & 100 \\
\hline Niger & $2,369,061$ & $2,305,320$ & $4,674,381$ & $2,196,959$ & $2,477,422$ & 47 & 53 & 100 \\
\hline Plateau & $1,826,838$ & $1,836,590$ & $3,663,428$ & $2,161,423$ & $1,502,005$ & 59 & 41 & 100 \\
\hline FCT Abuja & $1,143,686$ & $1,049,927$ & $2,193,613$ & $1,543,593$ & 6880,020 & 69 & 31 & 100 \\
\hline Total & $12,242,517$ & $11,971,137$ & $24,213,654$ & $12,902,019$ & $11,311,635$ & 53 & 47 & 100 \\
\hline South & $12,499,055$ & $12,069,632$ & $24,568,687$ & $17,503,260$ & $7,065,427$ & 71 & 29 & 100 \\
\hline South East & $9,451,250$ & $9,481,065$ & $18,932,315$ & $14,467,278$ & $4,465,037$ & 76 & 24 & 100 \\
\hline South West & $16,498,932$ & $15,984,378$ & $32,483,310$ & $26,375,402$ & $6,107,908$ & 81 & 19 & 100 \\
\hline North West & $21,339,307$ & $20,487,123$ & $41,826,430$ & $20,990,176$ & $20,836,254$ & 50 & 50 & 100 \\
\hline North East & $11,451,287$ & $10,818,833$ & $22,270,120$ & $8,842,654$ & $13,427,466$ & 40 & 60 & 100 \\
\hline North & $12,242,517$ & $11,971,137$ & $24,213,654$ & $12,902,019$ & $11,311,635$ & 53 & 47 & 100 \\
\hline Central & & & & & & & & 100 \\
\hline National & $83,482,348$ & $80,812,168$ & $164,294,516$ & $101,080,789$ & $63,213,727$ & 62 & 38 & 100 \\
\hline
\end{tabular}

Table 2: Estimated Literacy Levels in the North-Central Geopolitical Zone NMEC, 2012

This level of literacy does not appear to effectively impact on the fast paced changing educational needs of the rural communities. Given the active economic life of the rural farmers, low income transporters, fishermen and pastoralist nomads; the rural thrift project groups, rural farmers' cooperatives and other rural community-based business enterprises are maturing into stronger bodies that require elaborate records management and banking services. Literacy skills are required to enable these groups engage in the essential transactions that include completing bank forms, reading instructions, reading signs and notices among other needs. Against this background, this action research process would possibly unravel the existing problems and also evolve practices that could improve the existing literacy practices through the contributions of the focus groups for further development of learning contents, language of instruction and incorporation of cultural components derived from the people's livelihood for better literacy outcomes.

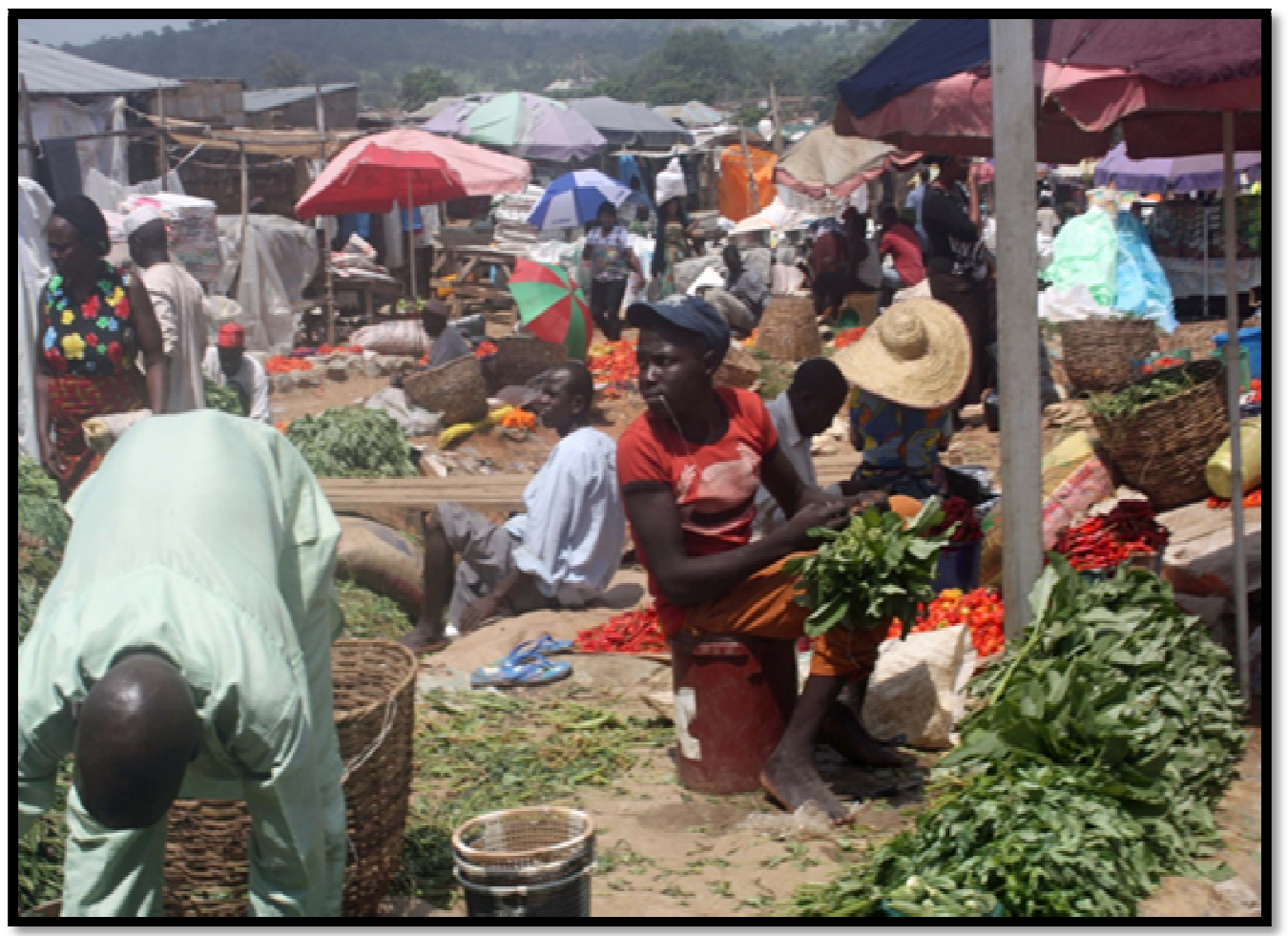

Figure 2: Rural Community Farmers' Business Activities That Incorporate

Thrift Collection, Which Requires Literacy Skills 


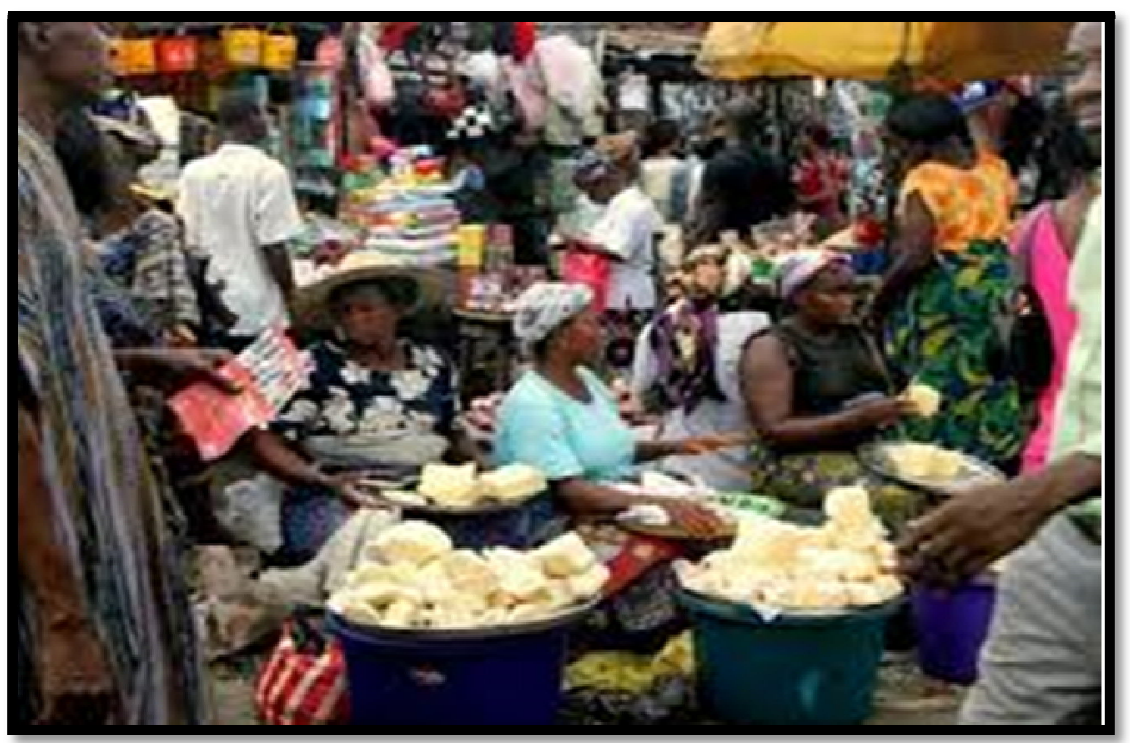

Figure 3: Rural Shea Butter Farmers/ Traders Who Also Engage in Cooperative Activities Requiring Literacy Skills

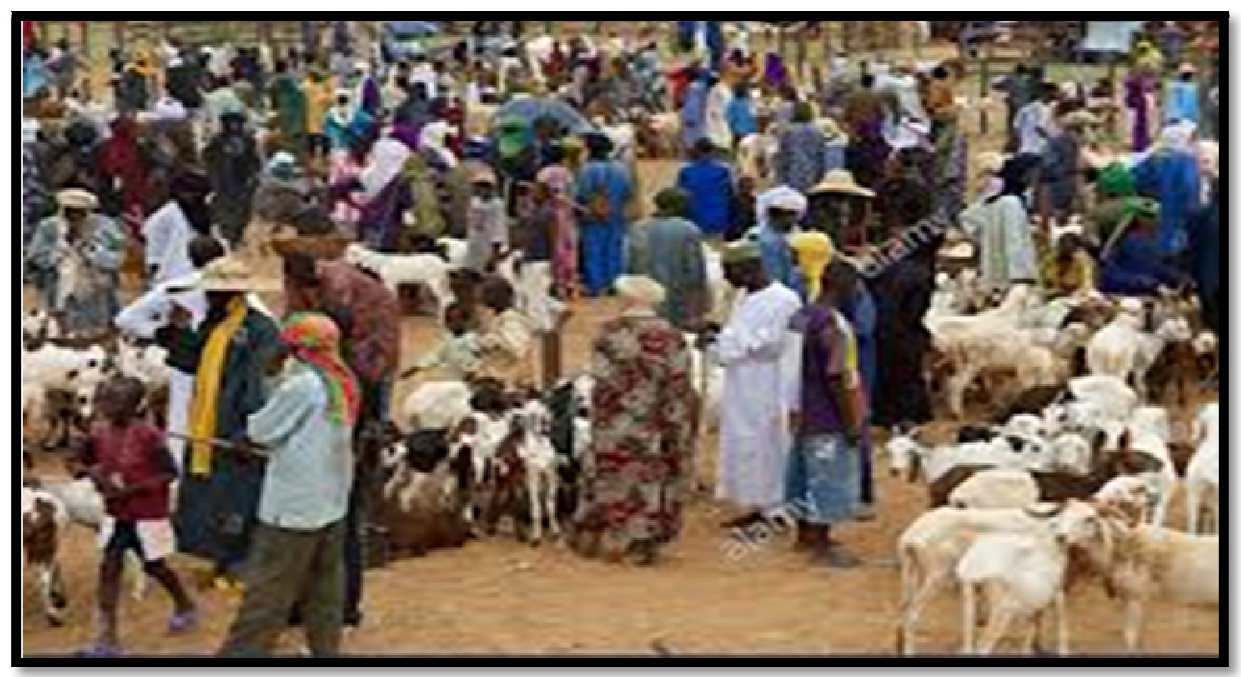

Figure 4: Livestock Farmers/ Traders Also Engage in Transactions Demanding Functional (Such as ICT) Literacy Skills

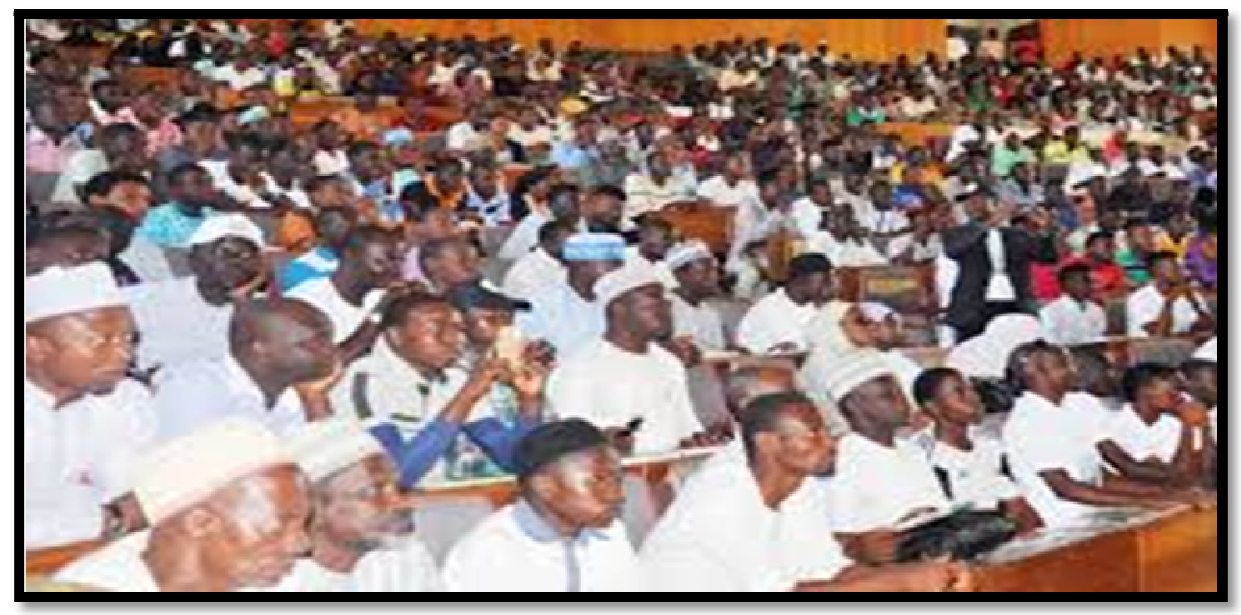

Figure 5: Borderline 53\% Literacy Level in Niger State Is Low Relative to Many Other States of Nigeria 


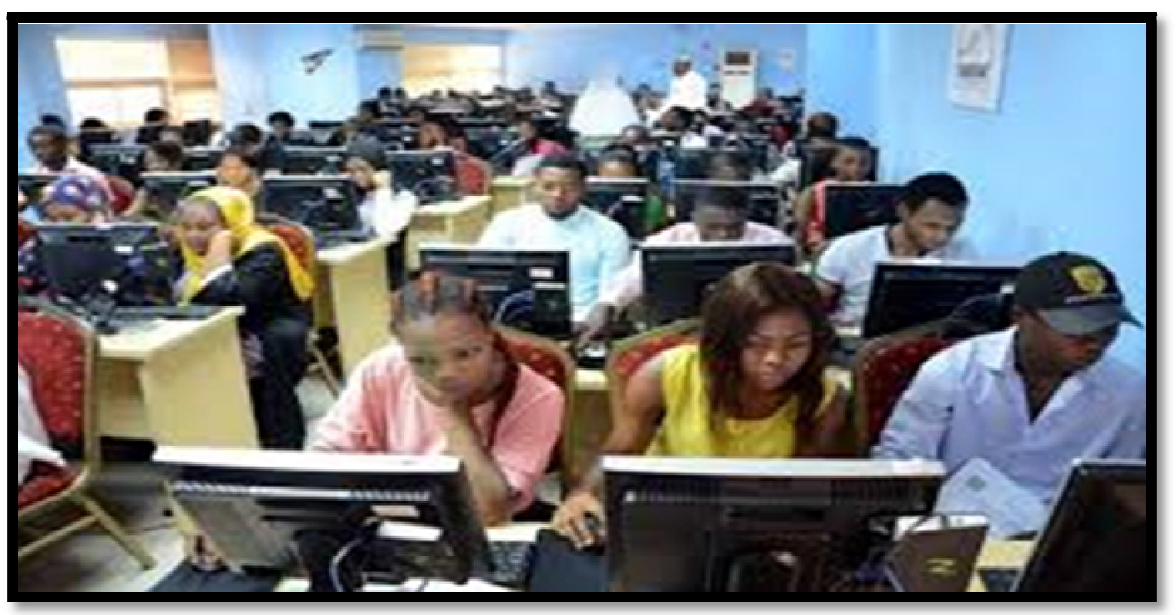

Figure 6: Computer Literacy Needs Cut Across All Economic/ Daily Living Activities of the People

\subsection{Objectives}

The study was guided by the following objectives:

- $\quad$ To find out the existing situation in terms of the literacy education practice and skills already acquired by the communities.

- $\quad$ To determine the existing gaps that should be closed to improve daily living standards of the communities.

\subsection{Benefits of the Action Research}

- An enriched multilingual literacy education practice developed through the discussions and contributions generated from focus groups in relation to the needs and aspirations of the beneficiaries.

- Increased enrolment and retention of learners to completion of learning programmes facilitated by an anticipated easier and more acceptable literacy teaching and learning modes.

- More inclusive literacy education process through better practice by literacy providers, curriculum developers and facilitators based on the capacity building experiences acquired from the action research.

\section{Review of Existing Literature}

Successful literacy education requires mother-tongue based systems so that the end target would not be the official language only, but also proficiency in at least two languages or more that include the mother tongue or language of the immediate environment; as stipulated in the national policy on education (FGN, 2014; Bamgbose, 2000a \& Adegbija, 2003). A six year study in Ife, Nigeria in which Yoruba was used as the medium of instruction for an entire primary education period significantly taught its readers that mother tongue does not prevent proficiency in language of wider communication. Rather the extended use of the mother tongue is better able to facilitate high levels of proficiency in the other target languages. This confirmed in an African setting, the second language acquisition theory, which holds that in well-resourced conditions with trained facilitators and adequate learning materials, second language teaching can facilitate successful transition to using the second language as medium of instruction at subsequent levels of comprehensive learning experiences (Heugh \& Tove 2010).

Multilingual education had a long history/ tradition in Africa reaching far into precolonial days. As has been pointed out by several authors such as Alidou (2003) and others, traditional education in precolonial Africa did not suffer from languages-in-education problems. The mother tongue was within each ethnic group for cultural socialization of the generation of people. Wolff (2011) stipulates three basic options for language-in-education policies with reference to the medium of instruction and facilitation of literacy education.

- Total endoglossic strategies, which connote mother tongue or national language medium of instruction throughout a system of education from basic to tertiary; to guarantee the desired and expected results.

- Total exoglossic strategies, which portray straight preference for English/French/ Portuguese without giving any room to mother tongue or indigenous lingua franca. These strategies tend to have poor effects on efficiency and effectiveness of learning.

- Combined endo and exoglossic strategies, which demonstrate subtractive multilingual models wherein the indigenous language of instruction is totally replaced in the long run; or additive multilingual models wherein the foreign language is added to the indigenous language that is retained throughout the education process.

The additive models have however proven to be most successful relative to other models such as the subtractive bilingual models. The most striking of all variables are the quality of facilitators of literacy education and their skills in the utilization of mother tongue/ national languages in the education process. Wolff (2011) and Alidou (2003) stress that what appears to be certain is that from a pedagogical/ andragogical perspective, it is far better to teach basic literacy learners in the mother tongue or a language they already know upon enrolling in an education/ learning programme. 
The number of adult illiterates in Nigeria is estimated at 23 million to 40 million (EFA Global Monitoring Report, 2010). Many also assume that the actual number may be as high as 52 million. In any case, these estimates offer an opportunity to foster more effective cooperation between government agencies, Non-Governmental Organizations for Literacy Support Services (NOGLASS) and private individual providers through regular review of the national operational guidelines for implementing literacy education curriculum contents on the grounds that choice of language of instruction and language policy in learning systems is critical for effective learning in all respects. It is also pertinent to address the persistent high illiteracy among Nigerian youths and Adults through the institutionalization of open learning at all levels by adopting ICT modes of literacy education delivery to complement the existing Literacy by Radio (LBR) and Face-to-face techniques. Digitalization is the current trend world-wide and most learnings seem to take place outside the conventional modes because of the overwhelming efficacy of the mobile devices in use among literate and non-literate populations. It follows that information communication technology is the ultimate resource for combating the scourge of illiteracy in combination with competent facilitators and appropriate content development.

\section{Methods}

The following stakeholders were involved in the participatory and collaborative action research:

IBB University, NMEC (Minna), State Agencies for Mass Education, NGOs and Communities comprised of facilitators and learners in literacy centres. These stakeholders synergized and partnered as follows:

- The communities provided answers to initial questions and explained the situations.

- The State Agency for Mass Education/ local government education officials provided portions of the required information/ data, and met logistical needs including hosting of all meetings.

- IBB University Researchers and professionals (experts) provided theoretical and conceptual frameworks, research procedure/ guidance and developed the data collection format.

- $\quad$ All stakeholders held meetings, carried out individual/ group assignments, exchanged ideas and shared facilities. An open-ended instrument was developed to elicit responses from members of the focus group during the focus group meetings that were held in the respective senatorial zones in Niger State. Within each zone one local government area was randomly included to participate in the study and participants were purposively drawn from the LGA the education officials. All the stakeholders at each meeting discussed freely within the context of the items in the research instrument, which was distributed to the stakeholders well ahead of time for the focus group meeting.

- The first stage of the study was focused on asking the initial questions to enable the research team explore the livelihood of the communities and find out the existing situation including the acquired skills, learning expectations, language differences and cultural practices that influenced literacy education practice (facilitation and learning achievements).

- The second stage assessed the context in terms of the identified learning expectations, language issues and other cultural elements. The research team used a hybrid process of combining participatory rural appraisal-PRA and ethnographic study style that included field observations, focus group discussions and interviews to find out existing skills gaps among the focus groups and facilitation gaps within the context of literacy education practice in the study locations.

There was consultation with the various groups and through exploratory questions such as Who did what? What skills existed? Which materials, methods, timing....Why this? Why that? (sometimes in the local/ familiar language); to ensure mutuality and to elicit the desired responses. Farming seasons and local market days were considered in arranging the field trips to ensure maximum cooperation and participation of the local people. By this process, the differences and diversities of the people were not only recognized, but it also projected what was already being accomplished through the eyes of the communities. These were all carried out cordially to ensure that best results were obtained to determine the existing gaps in the basic literacy education practice.

\begin{tabular}{|c|c|c|}
\hline State & Senatorial Zone & No. of Participants \\
\hline Niger & $\mathrm{A}$ & 48 \\
\hline & $\mathrm{B}$ & 52 \\
\cline { 2 - 3 } & $\mathrm{C}$ & 46 \\
\hline Total & & 146 \\
\hline
\end{tabular}

Table 3: The Focus Group Meetings Were Held in the

Three Senatorial Zones of Niger State by Drawing 146 Stakeholders as Total Participants

Each of the focus groups comprised

- Neo-literates

- Local government education officials

- Literacy facilitators

- State Agency for Mass Education officials 
- National Mass Education Commission officials (Minna)

- Researchers from IBBUL

\section{Results}

4.1. Senatorial Zone: A -Lapai Local Government Area

Predominant occupation was Farming within the zone

\subsubsection{Stage 1: Existing Literacy Experiences among Neo-Literate Group}

\subsubsection{Existing literacy primers}

- Hausa Primer

- English Primer

- Nupe Primer

- Designed Curriculum

- Language of literacy:

- English Language

- Hausa Language

\subsubsection{Reading Ability}

- Reading in Hausa was more fluent than English Language

\subsubsection{Numeracy}

- Numeracy is more effective in Hausa than in English

\subsubsection{Writing ability}

- $50 \%$ of the Learners wrote correctly in English and Hausa.

- $10 \%$ wrote only in Hausa

- $20 \%$ wrote correctly in Hausa but wrongly in English.

- $20 \%$ wrote correctly in English but wrongly in Hausa.

\subsubsection{Communication skill}

A lower percentage communicated in English while a higher percentage communicated in Hausa

\subsubsection{Stage 2: Existing Gaps in Literacy Experience among the Neo-Literates}

\subsubsection{Language of Literacy}

Nupe language should be included in instructional delivery

\subsubsection{Content of Literacy}

- Social Studies, Vocational Skills Acquisition including information communication technology skills contents should be included in their curriculum

\subsubsection{Method of literacy}

The major method used by facilitators was demonstration method

- The need exist to bring in models and other instructional resource materials and bring in innovative techniques like REFLECT,

- Literacy Shop among others.

- Timing/ schedule for literacy education:

- Timing was 2 p.m. to 4 p.m. which was considered appropriate.

\subsubsection{Facilitators of Literacy}

- Poor Remuneration

- Inadequate instructional facilities

- Training gaps

\subsubsection{Others}

- Supervision and Monitoring should be improved 
4.2. Senatorial Zone: B -Paikoro Local Government Area

Farming was the predominant occupation of the communities within the zone

\subsubsection{Stage 1: Existing Literacy Experience among Neo-Literate Groups}

4.2.1.1. Existing literacy primers

- Designed Curriculum of instruction

- Hausa Primer

- Nupe Primer

- English Primer

4.2.1.2. Language of Literacy

- English Language

- Hausa Language

\subsubsection{Reading ability}

- Reading in Hausa was more fluent than English Language

\subsubsection{Numeracy}

- Numeracy was more effective in Hausa than in English

\subsubsection{Writing ability}

- $20 \%$ wrote correctly in English but wrongly in Hausa.

- $50 \%$ of the Learners wrote correctly in English and Hausa.

- $10 \%$ wrote only in Hausa while

- $20 \%$ wrote correctly in Hausa but wrongly in English.

\subsubsection{Communication skill}

A lower percentage communicated in English while a higher percent communicated in Hausa

\subsubsection{Stage 2: Existing Gaps in Literacy Experience among the Neo-Literates}

\subsubsection{Language of literacy}

- Nupe language should be included in instructional delivery

\subsubsection{Content of literacy}

- Social Studies and Skills Acquisition should be included in their curriculum

\subsubsection{Method of literacy}

The major method used by Facilitators is Demonstration method

- The need to bring in models and other instructional resource

- Materials existed and these should be matched with

- innovative techniques such as REFLECT, Literacy Shop among other techniques.

4.2.2.4. Timing/ schedule for literacy education

- Timing for learning programme was scheduled at $2 \mathrm{p} . \mathrm{m}$. to $4 \mathrm{p} . \mathrm{m}$. to allow the women attend to chores before Commencement of the programmes.

\subsubsection{Facilitators of literacy}

- Poor Remuneration

- Inadequate instructional facilities

- Training gap

\subsubsection{Others}

- Supervision and Monitoring should be improved

\subsection{Senatorial Zone: C - Wushishi Local Government Area}

Farming was the predominant occupation within the zone. 


\subsubsection{Stage 1: Existing Literacy Experience Among Neo-Literate Group}

\subsubsection{Existing literacy primers}

- Hausa Primers and English Primers. There were other primers developed in other subject areas and on vocational skills.

\subsubsection{Language of Literacy}

Hausa and English

- $57 \%$ preferred to be instructed to learn in English

- $43 \%$ preferred to learn in HAusa

\subsubsection{Reading ability}

- $57 \%$ learners were able to read in English,

- $28 \%$ in Hausa

- $14 \%$ were unable to read at all

\subsubsection{Numeracy}

- $57 \%$ learners were able to count in English, while 43\% in Hausa

\subsubsection{Writing ability}

- $28 \%$ wrote in Hausa, 14\% wrote correctly in English

- $43 \%$ wrote correctly both in Hausa and English

\subsubsection{Communication skill}

- 4 learners out of 6 preferred to communicate in Hausa,

- 6 out of 10 preferred to write in English

\subsubsection{Stage 2: Existing Gaps in Literacy Experience among the Neo-Literates}

\subsubsection{Language of literacy}

- Absence of trained Facilitators to facilitate learning in the language of the immediate environment (Hausa)

\subsubsection{Content of literacy}

- Vocational skills should be incorporated into the learning experiences.

- These include such as knitting, welding, Home Economics, woodwork and information communications technology (ICT) skills.

\subsubsection{Method of Literacy}

- Absence of practical lessons, lack of learning materials and training gaps existed

\subsubsection{Timing/ Schedule for Literacy Education}

- The adult learners preferred to participate in the decision making about timing for learning programmes

\subsubsection{Facilitators of literacy}

- Inadequate number of qualified Facilitators

- Poor remuneration of facilitators

- Status of facilitators' appointment should be full-time and not part-time

\subsubsection{Others}

- Working materials and timely distribution of materials is important,

- Monitoring and Supervision, Unified curriculum and NGOs should be encouraged to support literacy education

\section{Discussion}

Given the existing situation in the three senatorial zones, which were represented by Lapai, Paikoro and Wushishi local government areas, the neo-literates in Niger State, Nigeria were exposed to literacy primer developed in English language, Hausa and Yoruba by the National Commission for Mass Literacy, Adult and Non-formal Education in Nigeria. Dividends of literacy education efforts in the area were observed in the efforts made by the neo-literates to practice and enjoy their literate status in the performance of daily living and business activities. Majority of them read in English language, a good number read more fluently in Hausa and others preferred to read in Hausa. The computation skills were used continuously in Hausa 
more than in English language. Some of the neo-literates communicated effectively verbally/writing in English language. Many opted to write in Hausa and others preferred communication in Hausa. These performances were reflected in various percentages as records in the result above. Apparently, the outcomes indicated that extended use of use of mother tongue or familiar language as stipulated in the National Policy on Education for basic literacy learners is better able to facilitate high levels of proficiency in the other target languages (FGN, 2014; Bamgbose, 2000a \& Adegbija, 2003).

On the identified gaps, it was obvious that no zone studied had any form of ICT mode of delivery, in spite of the universal digitalization of processes being adopted as a global trend. All methods of literacy education in the area were devoid of adequate appropriate resources for effective facilitation of literacy learning programmes. Each senatorial zone decried the neglect of various vocational skills acquisition programmes including computer appreciation. The persistent individual and collective request for increased access to support facilities for developing small and medium scale enterprises, was indicative of the people's zeal to engage in income generating activities towards self-sufficiency. The training gaps among facilitators of literacy education coupled with the poor supply of same in all zones was obvious. Many of them required computer literacy to key into the current digitalization trend in literacy education. Majority of the facilitators were engaged on part-time bases with poor and irregular remuneration. The resultant effect was poor commitment to the literacy facilitation assignment as they unsettled in search of greener pastures.

The women among the neo-literates showed promise for higher achievement if they were provided better learning conditions that includes open coaching through ICT; to enable them learn from wherever they are and at their own pace and time. This led to an understanding that within well-resourced conditions that include trained facilitators and adequate learning materials (ICT, internet of things, adequate quantity and quality of primers) second language teaching can facilitate successful transition to using the second language as medium of instruction for comprehensive learning at subsequent levels of culture and education (Heugh \& Tove 2010).

\section{Conclusion}

Investing in literacy must be viewed as a multi-faceted means of promoting basic education, which has literacy education at its root; and which in its self is the foundation upon which all other levels of education are built. Nigeria may not able to achieve a decent level of development without reaching a decent level of individual, communal and societal literacy. Given the current level of literacy in many parts of Niger state and Nigeria by extension, it is a task of great magnitude to precipitate sustainable change.

\section{Recommendations}

The following recommendations were made on the bases of the findings:

- Deepen democracy in the management and administration of literacy education in Nigeria to encourage participatory decision making among the stakeholders, concerning programme timing and schedule, content of learning programmes and language of instruction. This would not only increase enrolments, but it would also ensure that participants learn effectively, enjoy the outcomes and increase the completion rates in a sustainable mode.

- Higher investment in the development and distribution of quality learning materials for better and accelerated literacy education, is essential. These include primers and modules on various subjects in hard copies and soft categories uploaded in ICT devices as Apps, cartridges and compact discs- CDs. The essence is to enable effective participation of all stakeholders from anywhere, anytime and anyplace.

- Closing training gaps among all cadres of literacy education facilitators and ensuring better service conditions for them is a sure way to promote the pace of literacy education. It would ensure that individuals, communities and the Nigerian society at large gets value for resources invested in the education process.

- A unified curriculum in the long run, ensures that all persons are exposed to similar contents with provisions for expansion and diversification to match the various settings and environment in the complex Nigerian society, towards the ultimate prosperity of the recipients.

\section{References}

i. Adelore, O.A. Ojeketa, G, Omoregie, S. (2014). Training Manual for Facilitators in Non - formal Education. Abuja: UNESCO.

ii. Adegbija, E. (2003). Central Language Issues in Literacy and Basic Education: Three Mother tongue Education Experiments in Nigeria. In Adama Ouane. Towards a Multilingual Culture in Education. Hamburg: UNESCO Institute of Education.

iii. Bamgbose, Ayo (2003). Language and the African Rennaissance. Lessons from the South African Expirience. In H. ekkehard Wolff, Munster: Tied Tongues. The African Rennaissance as a Challenge for Language Planning. LIT.

iv. Heugh, K. and Tove, S. (eds, 2010). Multilingual Education Works: From the Periphery to the Centre. Delhi: Orient Blackswan.

v. Igbo, R.O. (2014) ed. Research in Adult and Non - formal Education towards RAYL Project in Nigeria: A collaboration of NMEC \& UNESCO UIL Germany. Abuja: Rhyce Publishers.

vi. NMEC (2012). Policy Guidelines for Adult and Non-formal Education in Nigeria. Abuja: NMEC

vii. NMEC (ND). Koyon Karatu Da Rubutu. Abuja. NMEC. 
viii. NMEC (ND). Literacy by Radio. Learners Primer. Abjua: NMEC, UNESCO, plac

ix. NMEC (ND). Karatu ta Hanyar Rediyo. Jagoran Maikoyo. Abjua: NMEC, UNESCO, plac

x. Quane, A. and Glanz, C. (2011). Optimizing learning, education and publishing in Africa: The language factor. Hamburg. UIL and ADEA.

xi. UNESCO Abuja (2012). Revitalization of adult and youth literacy in Nigeria: National strategicframework 2012 - 2015 and beyond. Abuja: UNESCO 